\title{
EFFECT OF REINFORCEMENT ON THE FRACTURE RESISTANCE OF ENDODONTICALLY TREATED MOLARS BY VARIOUS BONDED RESTORATIONS -AN IN VITRO STUDY
}

Ramandeep ${ }^{1}$, Jaidev Singh Dhillon ${ }^{2}$, Sachin Passi ${ }^{3}$, Raghav ${ }^{4}$, Ajay Chhabra ${ }^{5}$

${ }^{1}$ Assistant Professor, Department of Conservative Dentistry \& Endodontics, Christian Dental College, Punjab, India

${ }^{2}$ Professor \& Head, Department of Conservative Dentistry \& Endodontics, Gian Sagar Dental College and Hospital, Punjab, India

${ }^{3}$ Professor, Department of Conservative Dentistry \& Endodontics, Sri Sukhmani Dental College \& Hospital, Punjab, India

${ }^{4} \mathrm{MCH}$ Resident, Department of Neurosurgery, Christian Medical College \& Hospital, Punjab, India

${ }^{5}$ Professor \& Head, Department of Conservative Dentistry \& Endodontics, Bhojia Dental College \& Hospital, Himachal Pradesh, India

\begin{tabular}{l|l}
\hline \multicolumn{1}{c}{ ABSTRACT } \\
Objective: To compare and evaluate the fracture resistance of endodontically treated molars reinforced with \\
various bonded restorations and to study the type of fractures in various restorations. Methods: Forty \\
extracted mandibular molars were endodontically treated. MOD (Mesio-Occluso-Distal) cavities were \\
prepared and Mesio-Buccal cusp was reduced in all to provide cuspal coverage. All the teeth were then \\
divided into 4 groups. The cavities in group 1(control) were filled with high copper amalgam. Group 2 was \\
restored with direct resin composite. In group 3 after the priming and bonding procedures as in group 2, cavity \\
surfaces were coated with flowable resin composite. Before curing a piece of polyethylene ribbon fiber was \\
cut and coated with adhesive resin and was embedded inside the flowable composite. The resin composite \\
was cured with visible light cure (VLC) gun. For group 4, restorations were done according to the \\
recommendations provided by the manufacturers of SR Adoro (Ivoclar-Vivadent, Schaan, Liechtenstein) \\
composite material. Compressive fracture strength test was performed after at least 24 hours of the \\
fabrication of the specimens, by application of compressive loading in a Universal testing machine, applied \\
on the occlusal aspect of each specimen with a steel bar. The mean loads necessary to fracture were recorded \\
in Newton and the results were statistically analyzed. Results: Group 4 (indirect composite inlay) had the \\
greater fracture resistance and group 1(Amalgam) had the poorest. Difference between group 1 and 3 , group 1 \\
and 4 , group 2 and 4 were statistically significant. No statistically significant difference was found between \\
group 1 and 2, group 2 and 3, group 3 and 4 . Predominant type of fracture in group 1 and 3 was fracture of \\
tooth below cemento enamel junction at tooth restoration interface without mesio buccal cusp involvement. \\
In group 2 and 4 , predominant fractures were of tooth below cemento enamel junction through center of \\
restoration without mesio-buccal cusp involvement.
\end{tabular}

Key words: Root Canal Treatment, MOD cavity, Cusp coverage, Amalgam, Composite, Indirect composite, Fracture resistance.

\section{INTRODUCTION}

Endodontically treated teeth have seen dramatic changes in treatment modalities and restorative options for the last few years resulting in an increased success rate. After the successful cleaning and shaping and establishing a hermetic seal, the next important challenge is providing a good restoration. The most common options available to us are full coverage restorations or onlays, but with these options often the clinician may feel that too much tooth structure has been sacrificed for providing a so called protection to the tooth. Hence another option to restore these teeth can be MOD cavity preparation and restoration with some material which can reinforce the strength of tooth.

Various studies have been done in the past to evaluate the fracture resistance of endodontically treated teeth with MesioOccluso-Distal (MOD) cavities restored using different restorative techniques. ${ }^{1}$ Cusp coverage is advisable especially mesio buccal cusp of mandibular molars as the access cavity in these has to be essentially extended to the mesio buccal part of crown portion. A study done by Piyanee concluded that cuspal coverage is 
important to minimize the danger of marginal leakage and cuspal fracture in endodontically treated teeth. ${ }^{2,3}$

Recent studies have shown that dehydration after endodontic treatment does not weaken the dentinal structure with respect to compressive or tensile strengths. ${ }^{4}$ A study has also reported that endodontically treated teeth and their vital pairs exhibited similar biomechanical properties. ${ }^{5}$ Actually it is the combination of various factors like access cavity preparation, dental caries and loss of marginal ridge integrity which cause loss of tooth structure and hence reduction in resilience and fracture resistance of endodontically treated teeth. Access cavity alone causes $5-10 \%$ loss of relative stiffness, but marginal integrity loss causes $63 \%$ loss in cuspal stiffness. ${ }^{6}$ Hence tooth strength should be preserved primarily by preserving the remaining sound dentine. ${ }^{7}$ Thus a restoration which provides esthetics, function and reinforces the tooth structure as well would be much welcome. A conventional metal inlay is generally ruled out as it does not reinforce the tooth structure and also provides the wedging effect. Thus high chances of splitting of the tooth are there.

Last few years have seen the increased use of bonded restorations to achieve an ideal restoration, which promises us more conservation of tooth structure. With the bonded restorations we are moving towards a more conservative restoration era. Recent advances in adhesive dentistry have given us options to avoid full coverage crowns in restoring endodontically treated teeth. ${ }^{8}$

In this study various bonded restoration's fracture resistance has been compared. One of them is direct resin composite. A study done by Gelb M.N have shown that although both amalgam and direct composites can restore some strength of weakened teeth because of preparation over them, only etched and bonded composite restorations return the tooth to a fracture strength as high as or higher than that of sound or unprepared tooth. ${ }^{9,10}$

In recent years the development of fiber reinforced composite (FRC) is also being suggested to improve the strength of restorative materials. S. belli evaluated the effect of fiber insertion on fracture resistance of endodontically treated teeth with MOD preparations. They have found that use of polyethylene fiber under composite restorations have increased the fracture resistance of endodontically treated teeth significantly. ${ }^{11}$ There are also various other studies in the literature which support the use of fiber reinforced composite to increase the fracture strength of restored teeth. ${ }^{12,13,14} \mathrm{~A}$ study by $\mathrm{S}$ Belli has also shown the reduced microleakage by the use of polyethylene fiber with flowable composite under composite restorations. ${ }^{15}$ Ribbond (inc., Seattle, Washington USA) as polyethylene fiber was used in this study which is a reinforced ribbon made of ultra high molecular weight polyethylene fiber that has an ultra high elastic modulus. ${ }^{1}$ Still, there is limited research on its effect upon fracture resistance of tooth restored with combination of polyethylene fiber and composite in extensive MOD cavities.

The new SR Adoro (Ivoclar-Vivadent, Schaan, Liechtenstein) is a microfilled, light/heat cure composite. It is suitable for the fabrication of both metal supported and metal free restorations. It is an indirect composite system that offers several advantages over hybrid composite materials as regards wear, handling, plaque resistance and surface finish. Proper contacts and contours can be achieved. The range of indications of this composite includes inlays, onlays, and veneers. ${ }^{16}$

These materials were compared with silver amalgam in this study. It was used as a control group in this study. As various studies have shown that amalgam does not reinforces the tooth as other materials used. ${ }^{1,9}$

\section{METHODS AND MATERIALS}

\section{Selection and scaling of teeth:}

Forty freshly extracted human mandibular molar teeth with similar dimensions were selected without any caries or previous restorations. Ultrasonic scaling was done in all teeth to remove any calculus or other debris. All teeth were restored in Normal saline solution (Nirma Ltd, Gujarat) at room temperature throughout the study.

\section{Endodontic treatment of selected teeth:}

Standard endodontic access cavities were prepared using round and tapered fissured burs (Mani inc., Japan) in all teeth and canal orifices were located. Biomechanical preparation of all teeth was done using conventional step back procedure. Apices in all canals were prepared till number 30 with standard ISO K files (Mani inc., Japan). Recapitulation and irrigation was 
done with $2.5 \%$ sodium hypochlorite (Prime Dental Products Pvt. Ltd, Mumbai) and Normal Saline (Nirma Ltd, Gujarat). Canals were dried using absorbent paper points (Dentsply, Maillefer, Switzerland). Master Guttapercha cone were selected. All the prapared teeth were obturated with AH plus sealer (Dentsply, Maillefer, Switzerland) and Guttapercha (Dentsply, Maillefer, Switzerland) using lateral condensation technique. Endodontic finger spreaders (Mani Inc., Japan) were used to condense the Guttapercha cones (Figure 1).

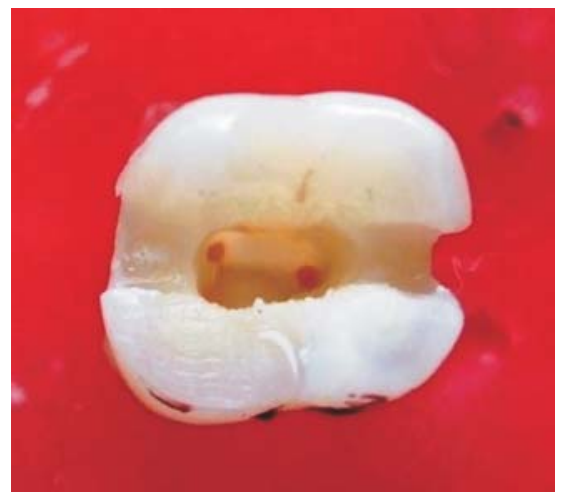

Figure 1: Obturated tooth with MOD cavity made

MOD cavity preparation and reduction of Mesio Buccal cusps:

MOD (Mesio-Occluso-Distal) cavities were prepared with straight and tapered fissure burs (Figure 1). The Bucco Lingual width of the occlusal isthmus was one half the width of the Intercuspal distance. The gingival cavosurface margin was located $1.0 \mathrm{~mm}$ coronal from the Cemento-Enamel junction. The depth of the cavity was $4.0 \mathrm{~mm}$ without proximal steps in all teeth. After this we reduced the Mesio-Buccal cusps of all molars by 2 millimeter (Figures 2, 3, 4). Which were covered with various restorative materials afterwards.

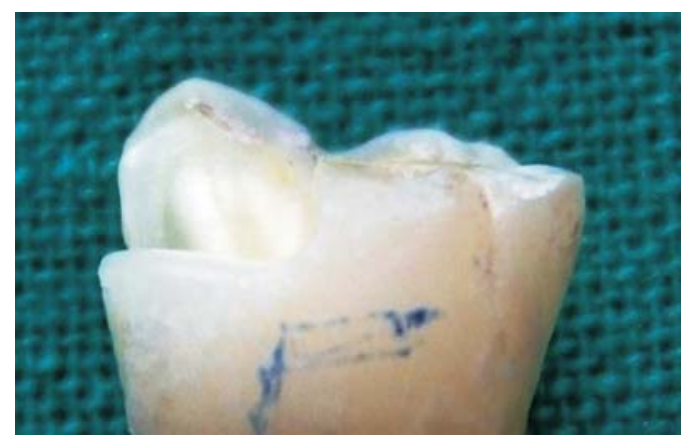

Figure 2: MB cusp reduction in one tooth
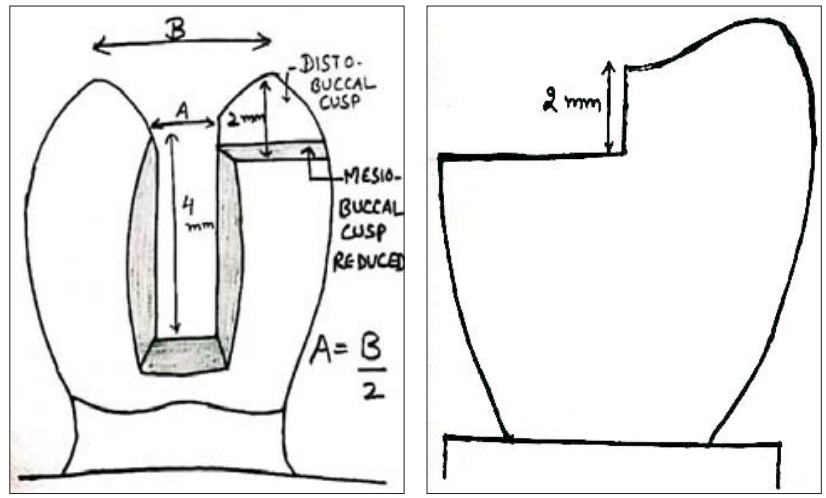

Figure 3 and 4: Diagrammatic representation of all measurements

\section{Restorations in four groups:}

Four groups were restored with following different materials.

Group 1: High Copper Amalgam (DPI Alloy). It was used as control.

Group 2: Direct Resin Composite (3M ESPE, Dental Products, St. Paul, USA)

Group 3: Polyethylene Ribbon Fibre (Ribbond, inc., Seattle, Washington USA) with Direct Resin Composite.

Group 4: Indirect Resin Composite (SR Adoro, Ivoclar-Vivadent, Schaan, Liechtenstein)

\section{Group 1 (Control)}

Toeffelmire retainer were applied to the teeth and amalgam was overfilled in the cavities. Carving of the condensed amalgam was done with amalgam carver to form Mesio Buccal cusp. Finishing and polishing was done with amalgam finishing kit (Shofuinc., Kyoto, Japan)

\section{Group 2}

After etching (Scotchbond Multi-purpose, 3M ESPE, Dental Products, USA) and bonding (3M ESPE, dental products, St. Paul, USA), matrix band was applied and cavities were filled with direct resin composite. The composite resin (Filtec 60, 3M ESPE) was placed in the cavities in increments of $2 \mathrm{~mm}$ thickness and each increment was light cured for 40 seconds. After the removal of the matrix band, the restorations were finished and polished using composite finishing kit (Sof-Lex). Mesio Buccal cusps were covered with same material. 


\section{Group 3}

After the etching and bonding procedures as in group 2, cavity surfaces were coated with flowable resin composites (Filtec 350, 3M ESPE). Before curing, a piece of polyethylene ribbon fibre (Ribbond, inc., Seattle, Washington USA) was cut and coated with adhesive resin and was embedded inside the flowable composite in Bucco- Lingual direction. Curing was done.

The remaining cavity was filled with same posterior resin composite (Filtec 60, 3M ESPE) which was used in group 2. Curing was done with visible light cure gun (Dentsply). Mesio Buccal cusps were covered. Finishing and polishing was done using composite finishing and polishing kit (Sof-Lex).

\section{Group 4}

Impressions of the prepared cavities were taken with Heavy body and light body impression material (3M ESPE, Dental Products, Germany) and working models were fabricated. Restoration of the cavity were done according to the recommendations provided by the manufacturer of SR Adoro composite (IvoclarVivadent, Schaan, Liechtenstein). Restoration was light cured as well heat cured in curing unit (Lumamet 100 furnace) and cemented into the natural tooth with the dual cure resin luting cement (3M ESPE Rely X, Dental Products, Germany) (Figure 5).

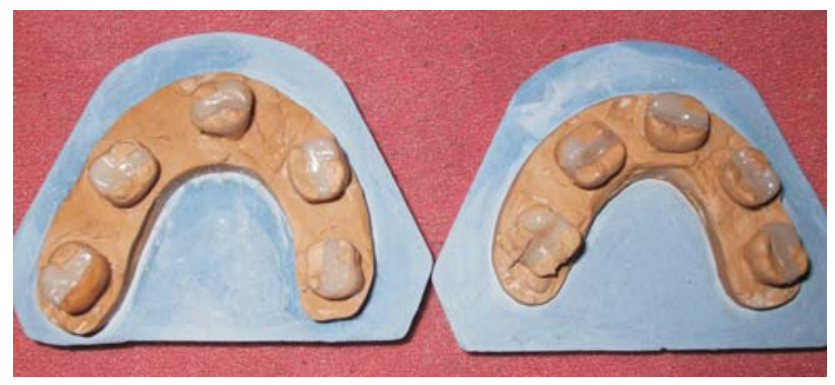

Figure 5: Indirect inlays made on working models

One operator performed all of the preparation and restoration procedures.

Mounting of all specimens in acrylic moulds with simulation of periodontal ligament:

Forty acrylic cylinders were fabricated by mixing the self cure acrylic resin, and pouring it into metal pipes of 2 inches height and $2 \mathrm{~cm}$ diameter. Specimens were embedded in acrylic resin exposing 1 millimeter of root surface just apical to buccal cervical line (to simulate alveolar bone) with two sheets of aluminium foils $(0.1$ $\mathrm{mm}$ thick) covering the root surface. Teeth were extracted after first sign of polymerization and foils were removed. Then silicon based impression material (3M ESPE, Dental Products, Germany) was injected in the space formed by the foils in the acrylic cylinder to simulate the periodontal ligament.

Each specimen was reinserted into the acrylic block exposing $1 \mathrm{~mm}$ of root surface just apical to buccal cervical line and held under digital pressure until the material sets. Excess material was removed with the help of B.P. knife. All specimens were again stored in normal saline until tested.

\section{Compressive strength testing:}

Compressive fracture strength test was performed after 24 hours of the fabrication of specimens (during this period, specimens were kept in saline solution), by application of compressive loading in a universal testing machine (Guru Nanak Dev University, Amritsar). A metal indentor of $6 \mathrm{~mm}$ diameter was fixed to the upper arm of the universal testing machine which was set to deliver an increasing load until fracture occurred. The crosshead speed was $1.0 \mathrm{~mm}$ per minute, and the load was applied to the occlusal inclines of the buccal and lingual cusps vertically down the long axis of the tooth. The bar was in contact with tooth structure as well as restoration (Figure 6). The force required to fracture each tooth was recorded in Newton. Each sample was then removed from the acrylic resin block and modes of fracture were evaluated.

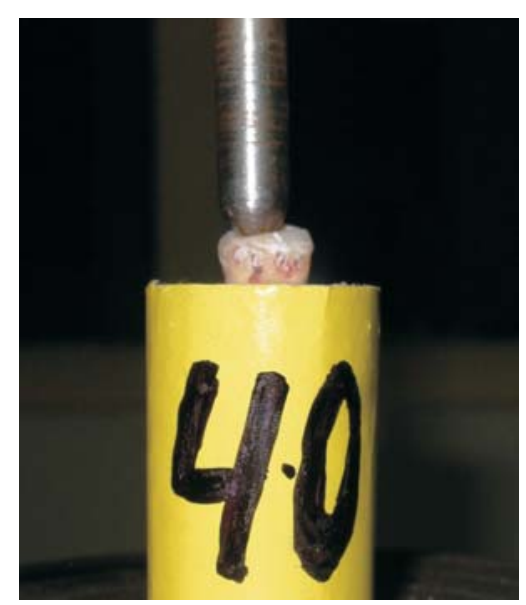

Figure 6: Steel bar touching cuspal inclines during fracture resistance test 


\section{RESULTS}

Group 4 (indirect composite inlay) had the greater fracture resistance and group 1(amalgam) had the poorest (table 1) (graph 1). Difference between group 1 and 3, group 1 and 4, group 2 and 4 were statistically significant. No statistically significant difference was found between group 1 and 2, group 2 and 3, group 3 and 4. Predominant type of fracture in group 1 and 3 was fracture of tooth below cemento enamel junction at tooth restoration interface without mesio buccal cusp involvement (Figure7) (Table 2). In group 2 and 4 predominant fractures were of tooth below cemento enamel junction through center of restoration without mesio-buccal cusp involvement (Figure8) (Graph2).

Table 1: Fracture Strength for the Various Restorations in Newtons (n)

\begin{tabular}{|l|c|c|c|c|}
\hline $\begin{array}{c}\text { Sample } \\
\text { S.NO }\end{array}$ & $\begin{array}{c}\text { GROUP-I } \\
\text { Amalgam (control) }\end{array}$ & $\begin{array}{c}\text { GROUP-II } \\
\text { Direct resin composite }\end{array}$ & $\begin{array}{c}\text { GROUP-III } \\
\text { Fiber reinforced } \\
\text { composite }\end{array}$ & $\begin{array}{c}\text { GROUP-IV } \\
\text { Indirect composite inlay }\end{array}$ \\
\hline 1 & 1369 & 2373 & 2865 & 2815 \\
\hline 2 & 1092 & 1625 & 3092 & 2364 \\
\hline 4 & 1861 & 1610 & 1504 & 2431 \\
\hline 5 & 1766 & 985 & 2799 & 2509 \\
\hline 6 & 1703 & 1650 & 3095 & 2048 \\
\hline 7 & 674 & 1840 & 2036 & 2365 \\
\hline 8 & 2034 & 1973 & 1796 & 2870 \\
\hline 9 & 2331 & 2780 & 1548 & 2527.7 \\
\hline 10 & 1619 & 2132 & 2539 & 306.79999 \\
\hline $\begin{array}{l}\text { Mean score } \\
\text { Standard } \\
\text { deviation }\end{array}$ & 2674 & 1812 & 2360.4 & \\
\hline
\end{tabular}

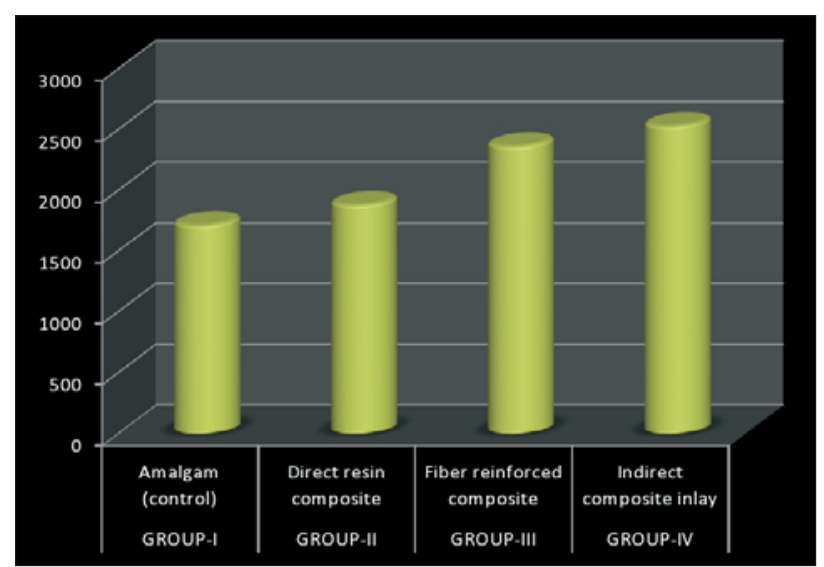

Graph 1: Fracture strength of the various restorations in Newtons $(\mathrm{N})$

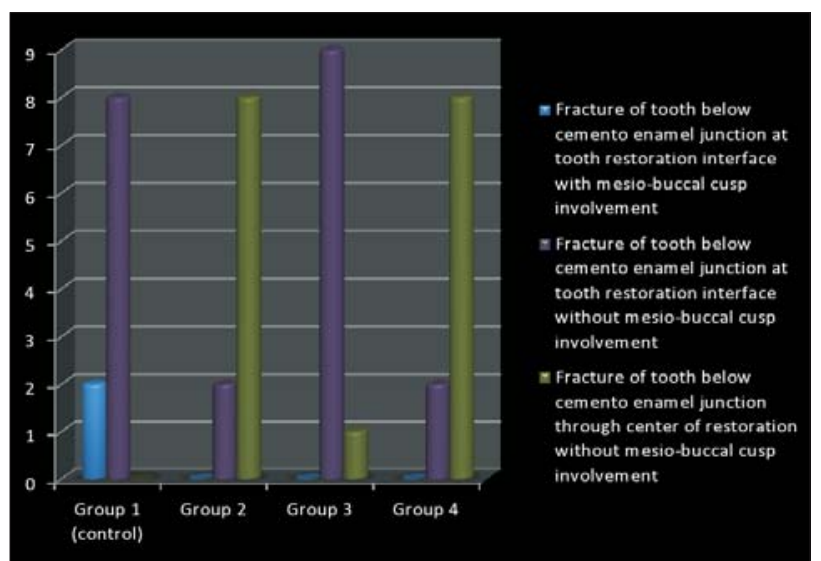

Graph 2: Failure patterns observed for each experimental groups

Table 2: Failure Patterns Observed For Each Experimental Group

\begin{tabular}{|c|c|c|c|c|c|}
\hline S.no. & Mode of fracture & Group 1 (control) & Group 2 & Group 3 & Group 4 \\
\hline 1 & $\begin{array}{l}\text { Fracture of tooth below cemento enamel junction at tooth restoration } \\
\text { interface with mesio-buccal cusp involvement }\end{array}$ & 2 & 0 & 0 & 0 \\
\hline 2 & $\begin{array}{l}\text { Fracture of tooth below cemento enamel junction at tooth restoration } \\
\text { interface without mesio-buccal cusp involvement }\end{array}$ & 8 & 2 & 9 & 2 \\
\hline 3 & $\begin{array}{l}\text { Fracture of tooth below cemento enamel junction through center of } \\
\text { restoration without mesio-buccal cusp involvement }\end{array}$ & 0 & 8 & 1 & 8 \\
\hline
\end{tabular}




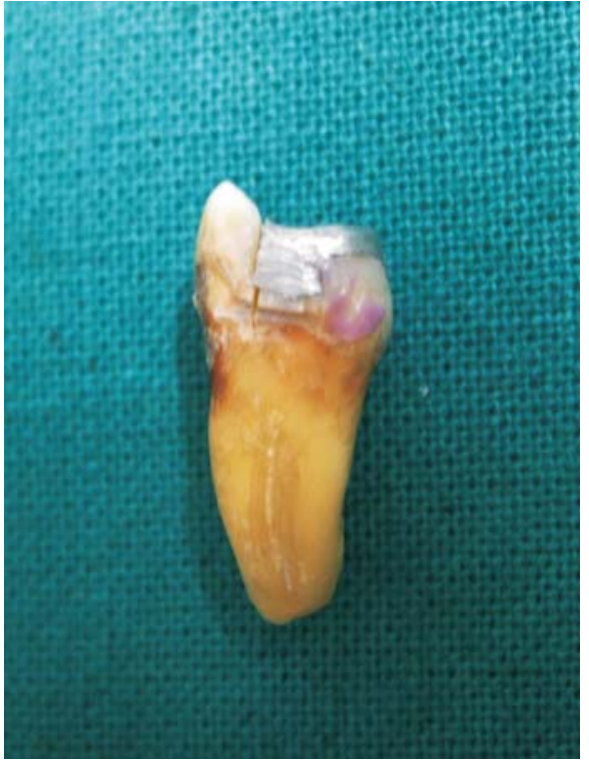

Figure 7: Mode of fracture in amalgam restoration showing fracture line through tooth-restoration interface

\section{DISCUSSION}

The successful root canal treatment depends upon establishing a hermetic seal and the next important challenge is to provide a good restoration. In the present study, we determined and compared the fracture resistance of endodontically treated molars restored with various conservative bonded restorations.

An ideal access cavity was prepared and precise biomechanical preparation and proper obturation was done. For the purpose of exact evaluation of fracture resistance and to simulate oral condition, a mesiooccluso-distal cavity was prepared (Figure1). Recent reports have indicated that the fracture resistance of endodontically treated teeth reduce because of tooth structure loss. ${ }^{17,18}$ The studies have shown that teeth loose $5 \%$ of their stiffness via access cavity only. On the other hand, occlusal and MOD cavity preparation causes $20 \%$ and $63 \%$ loss in tooth stiffness respectively. ${ }^{19}$ Thus our study wanted to evaluate the stiffness loss in the most common situations that we come across clinically.

Various studies have shown that cuspal deflection increases with increasing cavity size and was greatest after endodontic access. Hence, we should provide cuspal coverage to minimize the danger of cusp fracture. MOD cavities without any marginal ridge show more chances of cusp fracture than MO cavities as shown by Piyanee. ${ }^{2}$ Cusp coverage is advisable

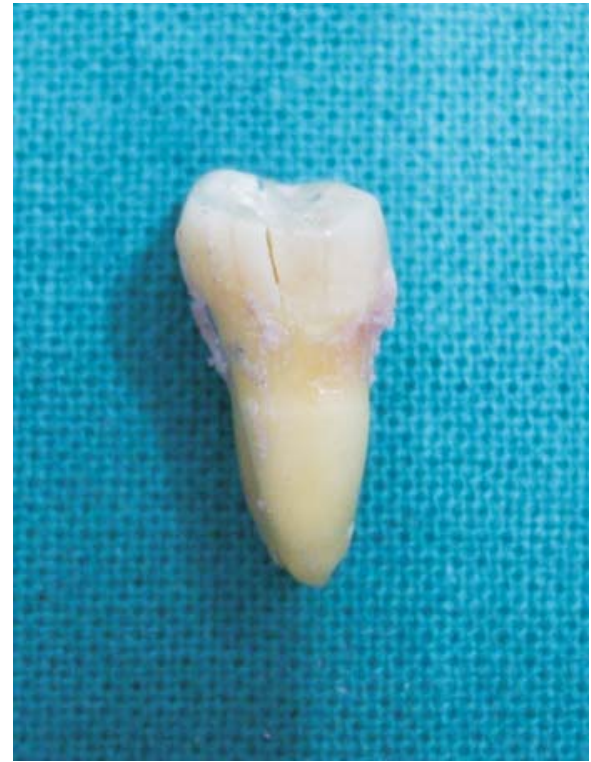

Figure 8: Mode of fracture in indirect composite inlay showing fracture line through restoration

especially mesio buccal cusp of mandibular molars as we need to extend the access cavity in these teeth to the mesio buccal part of crown portion. Accordingly, in present study, we provided cusp coverage to the mesio buccal cusp of mandibular molars. We reduced the cusps allowing a 2 millimeter layer of restorative material (Figures 2, 4).

Teeth were divided into four groups to restore them with following different materials.

Group 1: High copper Amalgam (control)

Group 2: Direct posterior composite

Group 3: Polyethylene ribbon fiber (Ribbond) with resin composite

Group 4: Indirect resin composite \{SR Adoro (Ivoclar-Vivadent, Schaan, Liechtenstein)\}

Amalgam is one of the oldest material used for restorations. However, various studies have shown that tooth rigidity does not increase with an intra coronal amalgam restoration. ${ }^{10}$ In this study, we accepted these points and used it as control group. We used high copper amalgam (DPI Alloy) because of its better physical and mechanical properties.

Second restorative material used in this study was direct composite resin (Filtec p60, 3M ESPE). According to manufacturer, Filtec p60 is an esthetic, light cured, radiopaque composite specifically 
designed for use in posterior direct or indirect restorations. The matrix of this composite consists of BIS-GMA (Bisphenol ADiglycidyl Ether Dimethacrylate), UDMA (Urethane Dimethacrylate), and BIS-EMA (Bisphenol A Polyethylene Glycol DietherDimethacrylate). This light cured resin is filled with $61 \%$ (VOLUME) Silica/Zirconia. The filler particle size is 0.01 micrometer to 3.5 micrometer with an average particle size of 0.6 micrometer. Filtec p60 exhibits about $25 \%$ less volumetric shrinkage upon curing. A study done by Feridun Hurmuzlu showed that Filtec p60 composite provides more fracture resistance than amalgam. ${ }^{20}$

Third material used in our study was polyethylene ribbon fiber \{Ribbond (inc., Seattle, Washington USA) $\}$, which is a reinforced ribbon made of ultra high molecular weight polyethylene fiber that has an ultra high elastic modulus. It is treated with cold gas plasma to enhance its adhesion to synthetic restorative materials, including chemically cured or light cured resin composites. The special network of this material allows for the efficient transfer of forces acting upon it. The method of insertion was similar as done by Cobankara in their study and some others. ${ }^{1,21,22}$

Fourth group in our study was a new indirect composite resin $\{\mathrm{S} R$ Adoro (Ivoclar-Vivadent, Schaan, Liechtenstein)\}. S R Adoro is a microfilled, light /heat -cure composite. It is suitable for the fabrication of both metal supported and metal free restorations. It offers several advantages over hybrid composite materials as regards wear, handling, plaque resistance and surface finish. It can provide proper contacts and contours. The range of indications of this composite includes inlays, onlays and veneers. ${ }^{16}$ In the present study, restoration of the cavity was done according to the recommendations by manufacturer of S RAdoro.

After all the restorations were completed, roots of all specimens were covered with two sheets of aluminium foils to achieve the thickness of periodontal ligament. They were then embedded in acrylic resin exposing 1 millimeter of root surface just apical to cervical line (to simulate cervical line). Teeth were removed from the acrylic after first sign of polymerization and aluminium foils were removed. Silicon based impression material (3M ESPE, dental products, Germany) was injected in the space taken by aluminium foils in acrylic cylinder (to give the effect of periodontal ligament). Each specimen was reinserted into the acrylic block exposing 1millimeter of root surface just apical to buccal cervical line and held under digital pressure until the material set. A study done by Soares et al concluded that the method of root embedment to simulate the periodontal ligament might modify the fracture modes. Simulation of periodontal ligament should be done with an elastomeric material that is able to undergo elastic deformation and reproduce the accommodation of the tooth in the alveolus, providing the non concentration of stresses in the cervical region of the tooth. ${ }^{23}$

While performing fracture resistance testing in this in vitro study axial forces were applied to the center of the occlusal surface. Studies had shown that best method for measuring the fracture resistance of posterior teeth is the use of a cylinder with a spherical end of a defined diameter. ${ }^{24,25}$ Use of a $6 \mathrm{~mm}$ steel sphere for fracture resistance testing by Soarce was found to be ideal for molars because it contacts the functional and non functional cusps in positions close to that found clinically. ${ }^{23}$ Accordingly, in current study we used a 6 $\mathrm{mm}$ steel cylinder with spherical end for compression loading (Figure 6).

Fracture resistance test was done in universal testing machine and data sent to the statistician for analysis. In the following paragraphs, we will discuss and compare all the four materials with each other.

Group 1 (Amalgam as control) versus group 2 (Direct resin composite):

The fracture resistance of amalgam was $1712.3 \mathrm{~N}$. which was less than that of direct resin composite $(1878 \mathrm{~N})$. This is because composite had reinforced the tooth through micro mechanical bonding to gain more fracture resistance than amalgam, which is a non bonded restoration. However the difference was not statistically significant. This was in accordance with the studies done by R.B. Joynt and others who did not find any significant difference in fracture resistance of teeth restored with amalgam and composite resin..$^{18,19,26}$

Group 1 (Amalgam) versus Group 3 (Fiber reinforced composite):

The fracture resistance of amalgam was $1712.3 \mathrm{~N}$. This was less than fiber reinforced group (2360.4). Difference was statistically significant. Various other studies have also shown similar result. ${ }^{1}$ Amalgam is a non bonded restoration. It does not adhere with the 
tooth. Hence it does not provide any reinforcing effect to the tooth. On the other hand fiber reinforced composite is a bonded restoration and a fiber embedded inside composite provided us the added advantage of transferring the forces acted upon it.

Group 1 (Amalgam) versus Group 4 (Indirect composite inlay):

The fracture resistance of amalgam was $1712.3 \mathrm{~N}$. This was very much less than indirect composite inlay $(2527.7 \mathrm{~N})$. Difference was highly significant statistically. Other studies have also shown similar results. ${ }^{1,27}$ This can be explained as above that composite provides reinforcing effect via its micromechanical bonding with the tooth. However amalgam does not bind to the tooth.

Group 2 (Direct resin composite) versus Group 3 (Fiber reinforced composite):

The fracture resistance of direct resin composite was $1878 \mathrm{~N}$. this was less than fiber reinforced composite group $(2360.4 \mathrm{~N})$. Difference was not significant statistically. This is in accordance with various studies done on Ribbond that had not shown significant difference with direct resin composite. ${ }^{1,14}$ The special network of fibers used in this study allowed for the efficient transfer of forces acting upon it and hence better fracture resistance. Various other studies have shown that polyethylene fiber use over or under MOD composite restorations significantly increased strength. ${ }^{28,1}$

Group 2 (Direct resin composite) versus Group 4 (Indirect composite inlay):

The fracture resistance of direct resin composite was $1878 \mathrm{~N}$. this was much less than indirect composite inlay $(2527.7 \mathrm{~N})$. Difference was significant statistically. This was in accordance with many studies that had shown that indirect composite inlays are always better than direct resin composites with regards to fracture resistance of endodontically treated teeth restored with them. ${ }^{1,29}$ The filler : matrix ratio is also higher in indirect composite inlay than traditional composites. The advantage of having control on the contacts and contours also cannot be ignored with indirect composite inlay.

Group 3 (Fiber reinforced composite) versus Group 4 (Indirect composite inlay):
The fracture resistance of fiber reinforced composite was 2360.4. This was although less than indirect composite inlay $(2527.7 \mathrm{~N})$. However difference was not statistically significant. Other studies had compared fracture resistance of fiber reinforced composite and indirect composite inlay and had not found significant difference. ${ }^{1,30}$ Both the materials had reinforced the tooth and both are bonded restorations but the higher filler: matrix ratio of indirect composite inlay might result in better fracture resistance value.

\section{Evaluation of the mode of fracture :}

Second aim of the present study was to study the mode of fractures in various restorations. In this aim, modes of failures were evaluated under magnification. We found that most common failures in group 1 (Amalgam) were at tooth-restoration interface (Figure 7). This is very well explained because of non bonded nature of amalgam. Fracture line extended sub gingival that require a crown lengthening followed by other restorative procedures.

However the mode of fracture that was most commonly found in all the bonded restorations (Group 2, 3 and 4) was found to be cohesive that is restorations fractured rather than the tooth restoration interface (Figure8). This was in accordance to the previous studies on mode of fracture of bonded restorations, thus proving again that bonded restorations are able to reinforce the tooth which is not as the case with amalgam. . $^{30,31,32}$

\section{CONCLUSION}

Within the parameters of this study, the following can be inferred:

- Indirect composite inlay (Group 4) had highest values of fracture resistance, so it is recommended by us as it also shows more control on contact and contours.

- The authors of the study feel that Indirect composite inlay method can replace a full coverage restoration or an extracoronal restoration in case the loss of tooth structure is not extensive i.e. cavity limited to being an mod cavity within the confines of $1 / 2$ intercuspal width.

- With regard to mode of fracture, fracture occurred within the restoration rather than tooth restoration interface, which is again a positive point for using an Indirect composite inlay. 
- With these results authors would like to conclude that the era of more conservative restorations like the one used in this study is a step in the right direction, but further in vitro and clinical trials are required to make them a permanent treatment modality.

\section{REFERENCES}

1. Cobankara FK, Unlu N, Cetin AR, Ozcan HB. The Effect of different restoration techniques on the fracture resistance of endodontically treated molars. Operative Dentistry 2008; 33: 526-33.

2. Panitvisai P, Messer HH. Cuspal deflection in molars in relation to endodontic and restorative procedures. Journal of Endodontics 1995; 21:57-61.

3. Cavel WT, Kelsey WP, Blankenau RJ. An in vivo study of cuspal fracture. Journal of Prosthetic Dentistry 1985; 53: 3841.

4. Hurmuzlu F, Kiremitci A, Serper A, Altundasar E, Siso SH. Fracture resistance of endodontically treated premolars restored with ormocer and packable composite. J Endod 2003; 29: 838-40.

5. Smith CT, Schuman N. Restoration of endodontically treated teeth: A guide for the restorative dentist. Quintessence Internationale 1997; 28: 457-62.

6. Rodrigues FB, Paranhos MPG, Spohr AM, Oshima HMS, Carlini B, Burnett Jr LH. Fracture resistance of root filled molar teeth restored with glass fibre bundles. Int Endod $\mathrm{J}$ 2010; 43: 356-62.

7. Opdam NJM, Bronkhorst EM, Roeters JM. Longevity and reasons for failure of sandwich and total etch posterior composite resin restorations. Journal of Adhesive Dentistry 2007; 9: 469-75.

8. Sorrentino R, Salameh Z, Zarone F. Effect of post retained composite restoration of MOD preparations on the fracture resistance of endodontically treated teeth. Journal of Adhesive Dentistry 2007; 9:49-56.

9. Gelb MN, Barouch E, Simonsen RJ. Resistance to cusp fracture in class II prepared and restored premolars. Journal of Prosthetic Dentistry 1986; 55: 184-86.

10. Mccullock AJ, Smith BGN. In vitro studies of cusp reinforcement with adhesive restorative material. British Dental Journal 1986; 161: 450-52.

11. Belli S, Erdemir A, Ozcopur M. The Effect of fibre insertion on fracture resistance of root filled molar teeth with MOD preparations restored with composite. Int Endod J 2005; 38: 73-80.

12. Freilich MA, Meiers JC, Duncan JP. Clinical evaluation of fibre-reinforced fixed bridges. Journal of American Dental Association 2002; 133: 1524-34.

13. Garoushi SA, Ballo AM, Lassila LVJ, Vallitu PK. Fracture resistance of fragmented incisal edges restored with fibre reinforced composite. Journal of Adhesive Dentistry 2006; 8: 91-95.

14. Meiers JC, Kazemi RB, Donadio M. The influence of fibre reinforcement of composites on shear bond strengths to enamel. Journal of Prosthetic Dentistry 2003; 89: 388-93.

15. Belli S, Orucoglu H, Yildirim C, Eskitasciglu G. The Effect of fibre placement or flowable resin lining on micro leakage in class II adhesive restorations. Journal of Adhesive Dentistry
2007; 9: 175-94.

16. Fonseca RB, Fernandes-neto AJ, Corer-sobrinho L. The influence of cavity preparation design on fracture strength and mode of fracture of laboratory-processed composite resin restorations. Journal of Prosthetic Dentistry 2007; 98: 277-84.

17. Bader JD, Shugars DA, Martin JA. Risk indicators for posterior tooth fracture. Journal of American Dental Association 2004; 135: 883-92.

18. Joynt RB, Wieczkowski G, Klickowski R. Effects of composite restorations on resistance to cuspal fracture in posterior teeth. Journal of Prosthetic Dentistry 1987; 57: 431-35.

19. Reeh ES, Messer HH, Douglas WH. Reduction in tooth stiffness as a result of endodontic and restorative procedures. $\mathrm{J}$ Endod 1989; 15: 512-16.

20. Hurmuzlu F, Serper A, Siso SH. In vitro fracture resistance of root filled teeth using new generation dentine bonding adhesives. Int Endod J 2003; 36: 770-73.

21. Deliperi S, Bardwell DN. Reconstruction of non vital teeth using direct fibre reinforced composite resin: A pilot clinical study. Journal of Adhesive Dentistry 2009; 11: 71-78.

22. Oskoee PA, Ajami AA, Navimipour EJ, Oskoee SS, Sadjadi J. The effect of three composite fibre insertion techniques on fracture resistance of root filled teeth. IntEndod J 2009; 35: 413-16.

23. Soares CJ, Pizi EC, Fonseca RB, Martins LR. Influence of root embedment material and periodontal ligament stimulation on fracture resistance tests. Brazilian Oral Research 2005; 19: 11-16.

24. Burke FJ, Wilson NH, Watts DC. The Effect of cavity wall taper on fracture resistance of teeth restored with resin composite inlays. Operative Dentistry 1993; 18: 230-36.

25. Burke FJT, Wilson NHF, Watts DC. Fracture resistance of teeth restored with indirect composite resins: The effect of alternative luting procedures. Quintessence Internationale 1994; 25:269-75.

26. Stele A, Johnson BR. In vitro fracture strength of endodontically treated premolars J Endod 1999; 25: 6-9.

27. Hitz T, Ozcan M, Gohring TN. Marginal adaptation and fracture resistance of root canal treated mandibular molars with intracoronal restorations: Effect of Thermo cycling and mechanical loading. Journal of Adhesive Dentistry 2010; 12 : 279-86.

28. Belli S, Erdemir A, Yildirim C. Reinforcement Effect of polyethylene fibre in Root filled teeth: comparison of two restoration techniques. Int Endod J 2006; 39: 136-42.

29. Coelho-de-souza FH, Camacho GB, Demarco FF, Powers JM. Fracture resistance and gap formation of MOD restorations: Influence of restorative technique, bevel preparation and water storage. Operative Dentistry 2008; 33: 37-43.

30. Plotino G, Buono L, Grande NM, Lamorgese V, Soma FC. Fracture resistance of endodontically treated molars restored with extensive composite resin restorations. J Prosth Dent 2008; 99: 225-32.

31. Soares CJ, Martins RM. Fracture resistance of teeth restored with indirect- composite and ceramic inlay systems. Quintessence Internationale 2004; 35: 281-86.

32. Soares PV, Santos-filho PCF, Martins LRM, Soares CJ. Influence of restorative technique on the biomechanical behaviour of endodontically treated maxillary premolars. Part I: Fracture resistance and fracture mode. Journal of Prosthetic Dentistry 2008; 99: 30-37.

\section{Source of Support: Nil, Conflict of Interest: None Declared}

